IZA DP No. 5543

Managerial Incentives and Favoritism in Promotion Decisions: Theory and Field Evidence

Johannes Berger

Claus Herbertz

Dirk Sliwka

March 2011 


\title{
Managerial Incentives and Favoritism in Promotion Decisions: Theory and Field Evidence
}

\author{
Johannes Berger \\ University of Cologne \\ Claus Herbertz \\ University of Cologne \\ Dirk Sliwka \\ University of Cologne \\ and IZA
}

Discussion Paper No. 5543
March 2011

IZA

P.O. Box 7240

53072 Bonn

Germany

Phone: +49-228-3894-0

Fax: +49-228-3894-180

E-mail: iza@iza.org

Any opinions expressed here are those of the author(s) and not those of IZA. Research published in this series may include views on policy, but the institute itself takes no institutional policy positions.

The Institute for the Study of Labor (IZA) in Bonn is a local and virtual international research center and a place of communication between science, politics and business. IZA is an independent nonprofit organization supported by Deutsche Post Foundation. The center is associated with the University of Bonn and offers a stimulating research environment through its international network, workshops and conferences, data service, project support, research visits and doctoral program. IZA engages in (i) original and internationally competitive research in all fields of labor economics, (ii) development of policy concepts, and (iii) dissemination of research results and concepts to the interested public.

IZA Discussion Papers often represent preliminary work and are circulated to encourage discussion. Citation of such a paper should account for its provisional character. A revised version may be available directly from the author. 
IZA Discussion Paper No. 5543

March 2011

\section{ABSTRACT}

\section{Managerial Incentives and Favoritism in Promotion Decisions: Theory and Field Evidence}

This paper investigates the effects of managerial incentives on favoritism in promotion decisions. First, we theoretically show that favoritism leads to a lower quality of promotion decisions and in turn lower efforts. But the effect can be mitigated by pay-for-performance incentives for managers who decide upon promotion. Second, we analyze matched employer-employee survey data with detailed firm level information on managerial incentive schemes and find that perceived promotion quality is indeed substantially higher when managers receive performance-related pay or participate in gain sharing plans.

JEL Classification: J33, M51, M52, M54, J71

Keywords: incentives, favoritism, nepotism, tournaments

Corresponding author:

Dirk Sliwka

University of Cologne

Herbert-Lewin-Str. 2

50931 Köln

Germany

E-mail: dirk.sliwka@uni-koeln.de 


\section{Introduction}

In most jobs work performance is not perfectly reflected in objective performance measures. As a consequence superiors are often asked to rate their subordinates subjectively, which gives them the possibility to favor one subordinate over another. As a consequence, performance appraisals may be biased, not reflecting actual work performance but the supervisor's personal preferences for her subordinates. If internal promotion decisions are based on subjective performance appraisals, favoritism may eventually result in not promoting the best but those who are best liked.

To avoid favoritism, pay and promotions are sometimes solely determined by seniority and other bureaucratic rules which of course also bear the risk of poor promotion decisions (Prendergast and Topel (1996), Marsh (1960)). Another solution has been suggested by Prendergast and Topel (1993) who claim that "a means of aligning the supervisor's incentives with those of the organization is to tie rewards to promotion and to make the supervisor responsible for the output of the job to which his subordinates are promoted" (Prendergast and Topel (1993), p. 360).

In this paper we investigate this idea in detail and analyze the relationship between managerial incentives and promotion decisions. First, we theoretically explore the effect of favoritism on managers' promotion decisions. Favoritism indeed leads to poor promotion decisions as the more able subordinate is less likely promoted. Workers anticipate their superior's bias and reduce efforts in promotion tournaments. Thus favoritism not only harms the company ex-post by putting the wrong people into management positions but it also reduces effort supply and therefore expected company earnings exante. Tying the manager's salary to workers' performances makes favoritism costly and leads to better promotion decisions.

For testing theoretically predictions, we use a unique employer-employee matched data set collected on behalf of the German Federal Ministry of Labor and Social Affairs by the Great-Place-to-Work Institute, a company 
specialized in conducting employee surveys, in 2006. The data set is a representative sample of 305 German firms containing company-level information on management practices. In addition, in each of the firms an employeesurvey has been conducted containing detailed information about employee perceptions of approximately 36,000 individuals. In contrast to researchers who try to assess promotion quality as an outsider to the firm, employees have inside knowledge and are in a good position to judge whether indeed the best people are promoted. We thus focus on a standardized item contained in the employee-survey which measures if "promotions go to those who best deserve them". In our analysis we use aggregated employee responses to this item to compare promotion quality across companies.

Indeed, we find that the quality of promotion decisions is significantly higher in firms in which managerial incentive schemes are used. Furthermore, the data suggest that even lower powered incentive schemes suffice to reduce favoritism in promotions which is well in line with the predictions of the formal model.

The remainder of the paper is organized as follows. In the next section we summarize the related literature. In section 3 we analyze our theoretical model to derive predictions on the consequences of managerial pay for promotion decisions. Section 4 describes our data set and the main variables used for our empirical analysis. Section 5 includes our main empirical results while section 6 discusses our results and summarizes our main findings.

\section{Related Literature}

The role of favoritism and social connectivity in firms has gained considerable attention in theoretical economic research in recent years. Prendergast and Topel (1996) were among the first to point out that personnel preferences towards employees may lead to favoritism and biased performance appraisals in firms. In their model supervisors derive utility from biasing 
performance appraisals according to individual preferences. High powered worker incentives lead to a stronger bias in performance evaluations. Furthermore, favoritism leads to a misallocation of workers to jobs and a distortion in incentives. Disentangling workers' pay from performance appraisals and introducing pure bureaucratic rules may constrain favoritism in their model. Prendergast (2002) extends this framework and shows that when performance appraisals become generally less valuable under uncertainty, the additional costs of favoritism associated with an increase in worker incentives are low. However, both papers do not study the connection between managerial incentive schemes and favoritism, which is the key focus of our paper.

There are also some empirical studies on the potentially harmful influence of favoritism. Longenecker et al. (1987) and Bjerke et al. (1987), for instance, examined determinants of performance evaluations in a US company and the US Navy respectively. Both studies claim that political considerations rather than true performance are reflected in subjective evaluations. This is especially true if performance appraisals are tied to bonuses. Ittner et al. (2003) analyze a balanced scorecard bonus plan which is based on supervisors' subjective evaluations. Even if financial measures for evaluating subordinates are available, supervisors' discretion leads to strong favoritism in employees' bonus payments in the studied company and finally to the abolishment of the scorecard. Breuer et al. (2010) analyze personnel data from a call center organization arguing that social ties triggered by repeated interaction or small team size lead to biased performance evaluations by supervisors.

Several other studies have examined restaffing decisions in the presence of family ties, which can be seen as a prominent case of favoritism in firms. Pérez-González (2006) report a faster career as well as higher wages for family members in family firms. Kramarz and Skans (2007) find that young Swedish men frequently work in their father's plant while having higher initial wages and worse school grades than comparable colleagues. Bennedsen et al. (2007), Pérez-González (2006) and Vilallonga and Amit (2006) also 
find that CEO family succession leads to a significant drop in family firm performance displaying the inefficiencies caused by favoritism in succession and promotion politics. ${ }^{1}$

While the existence and negative influence of favoritism is well documented, possible remedies for it are less intensely studied. One remarkable recent exception is Bandiera et al. (2009) who analyze an exogenous change from a fixed wage to bonus scheme for supervisors in a large agricultural company. Under fixed wages managers favor socially connected workers by granting them a stronger support which leads to a large productivity gap between socially connected and socially unconnected workers. When supervisors receive a bonus based on workers' output they reallocate their support towards high ability workers causing a significant overall increase in productivity. We show that managerial bonus payments also substantially affect the quality of promotion decisons and provide evidence based on a large and representative sample of firms.

Finally, by combining survey data on management practices with more objective information across larger samples on different firms our paper adds to the emerging literature on investigating key issues in personnel economics and the economics of organizations as for instance recently advocated in Bloom and Van Reenen (2007). ${ }^{2}$

\section{The Model}

We consider a 3 stage model with a top manger $M$ and two heterogeneous agents $i=A, B$ competing for a middle manger position. In the first period, agents choose an unobservable effort level $e_{i t}$ and produce outputs

$$
s_{i 1}=a_{i}+e_{i 1}+\varepsilon_{i 1}
$$

\footnotetext{
${ }^{1}$ Two exceptions to these findings are Sraer and Thesmar (2007) and Anderson and Reeb (2003).

${ }^{2}$ See also Bloom and Van Reenen (2010).
} 
where $a_{i} \sim N\left(m_{a}, \sigma_{a}^{2} / 2\right)$ denotes agent $i$ 's time invariant and unknown ability. The error term is also normally distributed with $\varepsilon_{i 1} \sim N\left(0, \sigma_{\varepsilon}^{2} / 2\right)$. We assume $a_{i}$ and $\varepsilon_{i 1}$ to be independent and their distributions to be common knowledge. Providing effort yields effort $\operatorname{costs} \frac{c}{2} e_{i}^{2}$. Period 1 profit is given by

$$
\Pi_{1}=s_{A 1}+s_{B 1}
$$

In period 2 top manager $M$ observes performances $s_{i 1}$ and chooses which agent $\phi \in\{A, B\}$ is to be promoted to the middle manager position. The promoted agent receives a wage increase $\Delta w$.

In period 3, agents choose their effort level $e_{i 3}$, again produce $s_{i 3}=a_{i}+$ $e_{i 3}+\varepsilon_{i 3}$ and generate company profit

$$
\Pi_{3}=k \cdot s_{\phi 3}+s_{-\phi 3}
$$

where $s_{\phi 2}$ and $s_{-\phi 2}$ are the outputs of the promoted and non-promoted agent. With $k>1$ we assume a middle manager's performance to have larger impact on company profit.

The agents' utilities are simply the sum of their expected wages minus their effort costs. The top manager $M$ 's wage is given by $\alpha+\beta \cdot\left(\Pi_{1}+\Pi_{3}\right)$ where $\alpha$ is a fixed wage and $\beta$ measures the extent of profit sharing. Finally, we assume that the top manager may personally like the two agents to a different extent and therefore favor one over the other. Similar to Prendergast and Topel (1996) and Prendergast (2002) she receives a utility from favoritism of $\eta_{\phi} \cdot \Delta w$ such that the wage increase $\Delta w$ awarded to the promoted agent is weighted with a preference parameter $\eta_{i}$. Hence, her overall utility is

$$
\alpha+\beta \cdot\left(\Pi_{1}+\Pi_{3}\right)+\eta_{\phi} \cdot \Delta w
$$

We assume $M$ 's discount factor to be 1 and $\eta_{i}$ to be known by all players. Furthermore, we take all compensation parameters with the exception of $\beta$ as given and focus on the connection between $\beta$ and promotion decisions. 


\subsection{Equilibrium Analysis}

We now determine the Perfect Bayesian Equilibrium. In the absence of incentives, agents choose zero effort in stage 3 and produce according to their ability (see equation 2). At stage 2 the topmanager $M$ 's conditional expected utility for $\phi \in\{A, B\}$ depends on agents' period 1 performances $s_{A 1}$ and $s_{B 1}$ and is given by

$$
\begin{aligned}
V_{M}\left(\phi, s_{A 1}, s_{B 1}\right) & =E\left[\alpha+\beta \cdot\left(\Pi_{1}+\Pi_{3}\right)+\eta_{\phi} \cdot \Delta w \mid s_{A 1}, s_{B 1}\right] \\
& =\alpha+\beta k \cdot E\left[a_{\phi} \mid s_{\phi 1}\right]+\beta \cdot E\left[a_{-\phi} \mid s_{-\phi 1}\right]+\eta_{\phi} \cdot \Delta w .
\end{aligned}
$$

Hence, $M$ promotes agent $A$ if $V_{M}\left(A, s_{A 1}, s_{B 1}\right) \geq V_{M}\left(B, s_{A 1}, s_{B 1}\right)$ or

$$
E\left[a_{A} \mid s_{A 1}\right]-E\left[a_{B} \mid s_{B 1}\right] \geq \frac{\Delta \eta \cdot \Delta w}{\beta(k-1)}
$$

where $\Delta \eta=\eta_{B}-\eta_{A}$. In the absence of favoritism $(\Delta \eta=0)$ the RHS in equation 3 is zero. In this case, $M$ 's decision is solely driven by her expectations about agents' abilities and the agent who is expected to be more able gets promoted. Hence, the model basically boils down to a standard Lazear and Rosen (1981) type tournament model. Furthermore, pure ability based promotion decisions maximize the company's post promotional profit in equation 2. If, however, favoritism matters, $M$ gains additional utility from promoting the favored agent. The more $M$ favors an agent, the more likely it is that her promotion decision will not coincide with the profit maximizing decision. Furthermore, the higher $\beta$ the smaller this distortion will be which leads to the first result:

Proposition 1 Higher powered incentive schemes reduce the manager's inclination to follow her private preferences in the promotion decision. 
Anticipating $M$ 's decision in 3 agent $A$ 's expected utility is given by

$$
U_{A}=\operatorname{Pr}\left(E\left[a_{A} \mid s_{A 1}\right]-E\left[a_{B} \mid s_{B 1}\right] \geq \frac{\Delta \eta \cdot \Delta w}{\beta(k-1)}\right) \Delta w-\frac{c}{2} e_{A 1}^{2} .
$$

The conditional expectation about agent $i$ 's ability is given by

$$
E\left[a_{i} \mid s_{i 1}\right]=m_{a}+\frac{\sigma_{a}^{2}}{\sigma_{a}^{2}+\sigma_{\varepsilon}^{2}}\left(a_{i}+e_{i}+\varepsilon_{i 1}-m_{a}-\widehat{e}_{i 1}\right)
$$

where $\widehat{e}_{i 1}$ denotes $M$ 's belief about agent $i$ 's equilibrium effort choice. ${ }^{3}$ Substituting $M$ 's conditional expectation into agents' objective function yields

$$
E U_{A}=\Phi\left(\frac{e_{A 1}-e_{B 1}-\widehat{e}_{A 1}+\widehat{e}_{B 1}-\frac{\Delta \eta \cdot \Delta w}{\beta(k-1)} \frac{\sigma_{a}^{2}+\sigma_{\varepsilon}^{2}}{\sigma_{a}^{2}}}{\sqrt{\sigma_{a}^{2}+\sigma_{\varepsilon}^{2}}}\right) \Delta w-\frac{c}{2} e_{A 1}^{2}
$$

where $\Phi(\cdot)$ is the c.d.f. of the standard normal distribution. If an internal equilibrium exists ${ }^{4}$, the agents' optimal symmetric effort choices are therefore given by

$$
e_{A, B}^{*}=\frac{\Delta w}{c \sqrt{2 \pi\left(\sigma_{a}^{2}+\sigma_{\varepsilon}^{2}\right)}} \exp \left[-\frac{\Delta \eta^{2} \cdot \Delta w^{2}}{2 \beta^{2}(k-1)^{2}} \frac{\left(\sigma_{a}^{2}+\sigma_{\varepsilon}^{2}\right)}{\sigma_{a}^{4}}\right] .
$$

From this equation we directly obtain our second result:

Proposition 2 The agents' equilibrium effort levels are strictly decreasing in the degree of favoritism $\Delta \eta$ and strictly increasing in the power of managerial incentives $\beta$.

Favoritism towards subordinates does not only reduce future profits as on average less able agents are promoted. It also lowers ex-ante profits as

\footnotetext{
${ }^{3}$ For the conditional expectation of normally distributed random variables see for instance DeGroot (1970) p.167.

${ }^{4}$ Existence can be assured when $c$ is sufficiently large as the objective functions are then strictly concave.
} 
the agents anticipate that promotion decisions are note entirely driven by performance considerations. This mechanism weakens the link between performance and rewards and, in turn, makes exerting high efforts less attractive.

To illustrate the relationship between managerial incentives and promotion quality we derive the ex-ante probability of promoting the more able agent. Assume w.l.o.g. that $\Delta \eta>0$, i.e. agent $B$ is favored by $M$. The likelihood that indeed the agent is promoted who is expected to be more able is given by

$$
1-\operatorname{Pr}\left(0<E_{a n}\left[a_{A} \mid s_{A 1}\right]-E_{a n}\left[a_{B} \mid s_{B 1}\right]<\frac{\Delta \eta \cdot \Delta w}{\beta(k-1)}\right) .
$$

Inserting the conditional expectation (4) and simplifying yields that in equilibrium this probability is equal to

$$
\frac{3}{2}-\operatorname{Pr}\left(\Delta a+\Delta \varepsilon<\frac{\sigma_{a}^{2}+\sigma_{\varepsilon}^{2}}{\sigma_{a}^{2}} \frac{\Delta \eta \cdot \Delta w}{\beta(k-1)}\right) .
$$

As from an ex-ante perspective $\Delta a+\Delta \varepsilon$ is normally distributed with mean 0 and variance $2 \sigma_{a}^{2}+2 \sigma_{\varepsilon}^{2}$ this probability is

$$
\frac{3}{2}-\Phi\left(\frac{1}{2 \sigma_{a}^{2}} \frac{\Delta \eta \cdot \Delta w}{\beta(k-1)}\right) .
$$

The function is monotonically increasing in $\beta$ but becomes flat if $\beta$ is sufficiently large. ${ }^{5}$ Figure 1 displays plots of function 6 for different degrees of favoritism $\Delta \eta{ }^{6}$ Note that even at rather low levels of $\eta$ the probability that the wrong agent is promoted is $50 \%$ when there are no managerial incentives. But in this case even very low powered incentive schemes suffice to generate substantial efficiency gains. Of course, when the impact of favoritism is large

\footnotetext{
${ }^{5}$ Note that $\lim _{\beta \rightarrow \infty} \frac{\partial\left(\frac{3}{2}-\Phi\left(\frac{1}{2 \sigma_{a}^{2}} \frac{\Delta \eta \cdot \Delta w}{\beta(k-1)}\right)\right)}{\partial \beta}=0$.

${ }^{6}$ Figure 1 shows graphs for $w=10, k=3$ and $\sigma_{a}^{2}=5$ for values of $\Delta \eta=0.1,0.2$, or 0.4 .
} 


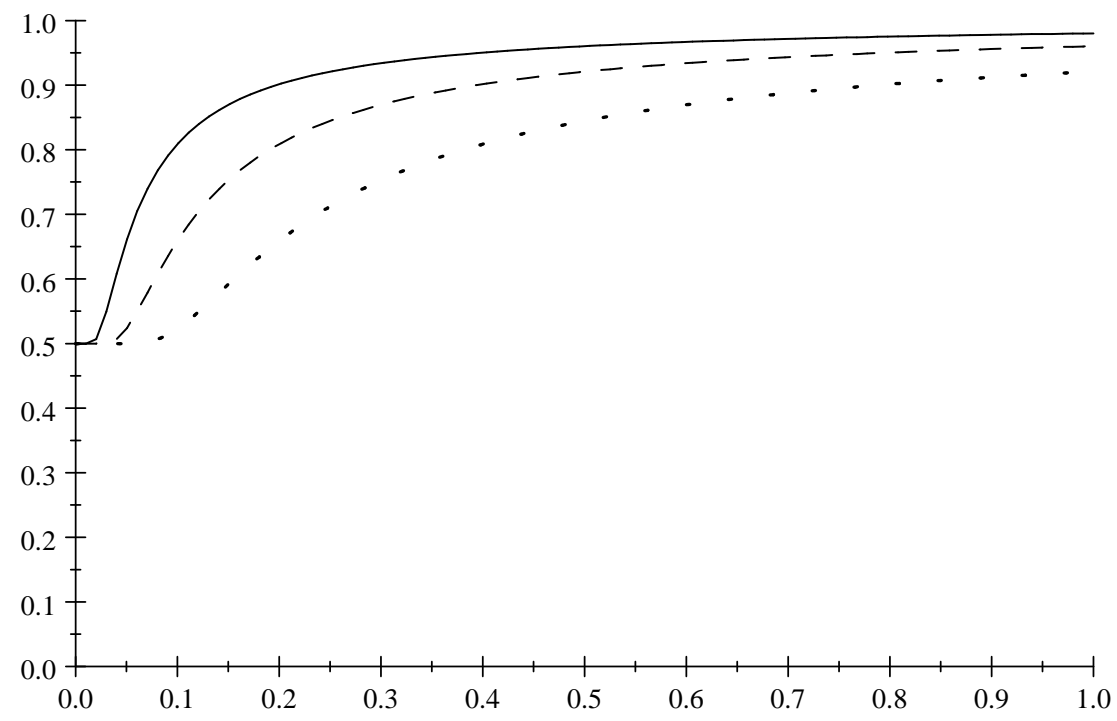

Figure 1: Probability that more able agents are promoted as a function of $\beta$

higher values of $\beta$ become necessary to reduce the bias.

\section{Data and Hypotheses}

Our data source is a 2006 employer-employee matched survey conducted by the Great-Place-to-Work Institute and the German Federal Ministry of Labor and Social Affairs. The data set is a representative sample of 305 German firms employing a minimum of 20 workers. For each firm the management provided company-level information on organizational facts, strategic goals and corporate values as well as on various management practices and the structure of compensation. Most of this information is provided separately for managers and workers in each firm. ${ }^{7}$

In addition to this firm-level information, a representative employee-

\footnotetext{
${ }^{7}$ More specifically, answers were provided for employees in supervisory function and the largest group of nonmanagerial employees, i.e. the core occupational group.
} 
survey was conducted at each sampled firm yielding over 36,000 observations in total. The employee survey includes 58 standardized items to be answered on a 5-point Likert scale which are designed to measure the level of trust, pride, and cooperation within firms. More precisely the items focus on the relationship among employees, between employees and management, and on their work environment.

Due to the random sampling process the 305 firms are almost evenly spread across the different industries in Germany. The majority of the sampled firms are small or medium sized. While the average number of employees amounts to 430 , the median lies at 157 . However, roughly $10 \%$ of the firms employ more than 1,000 workers including the largest firm in the sample with 14,000 workers.

The management survey includes detailed information on the structure of incentive pay in each firm. Each management representative stated whether wages for managers and workers in the corresponding firm include a performance related pay component. For both, managers and workers, we know the share of the average wage (in \%) determined by performance related pay (henceforth PRP). ${ }^{8}$

Figure 2 gives a descriptive overview of PRP usage across industries displaying the share of firms using PRP for managers and workers. While only less than half of all sampled firms use variable pay components for workers, the use of manager PRP varies from only $16 \%$ in the Public Sector to $90 \%$ in Financial Services. In total 168 out of 296 (57\%) firms use PRP for their managers. 9

In addition to the information on the strength of performance related pay

\footnotetext{
${ }^{8}$ To be precise, the items are "Does the compensation of the employees encompass a performance-based part? (yes/no)" and "How big is the variable share on average (in \%)" and "What are the shares of the following measures of success in this variable compensation component? (company success, success of the organizational unit (team, working group), personal performance, or other)". It is important to note that this does not refer to the actual payments in the studied year but the general structure of the compensation scheme.

${ }^{9} 9$ out of the 305 sampled firms did not provide information on PRP.
} 


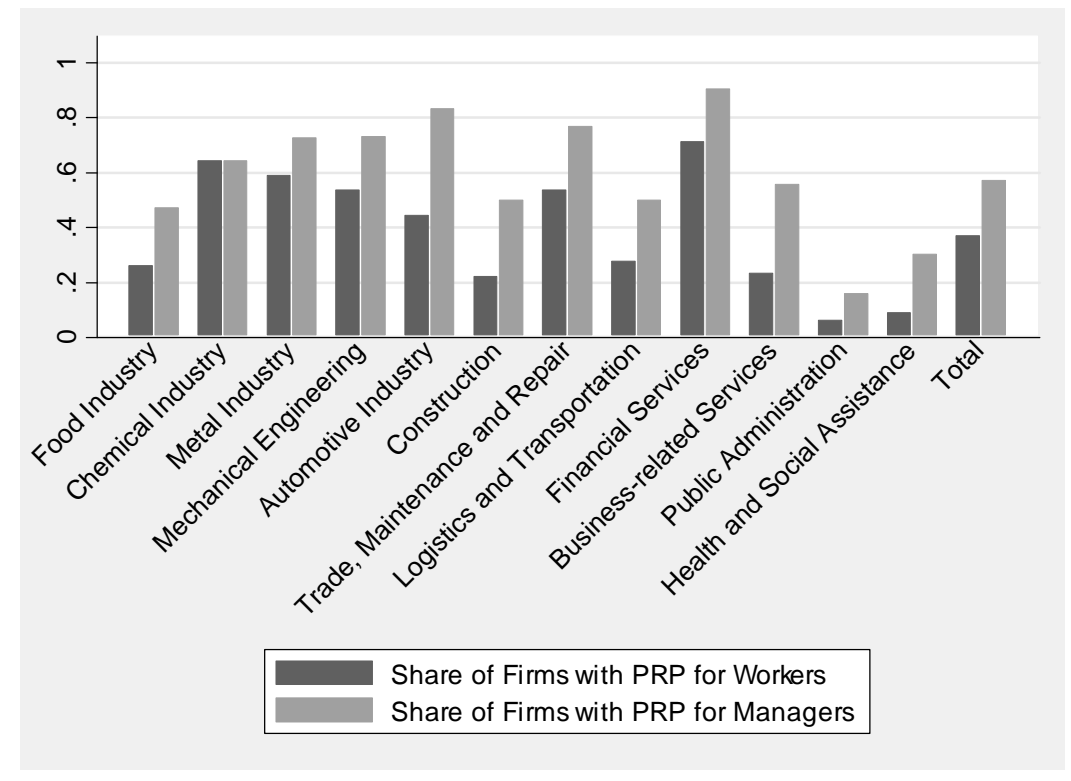

Figure 2: Utilization of Performance related Pay across German Industries

components the management survey also includes information on whether there is a gain sharing scheme or managers hold company assets. In contrast to manager PRP this information is only provided as a binary variable which we label as Manager Gain Sharing. 36 out of 295 (12\%) firms used such gain sharing plans for their managers. Together with manager PRP this variable will serve as our main independent variable in the upcoming analysis. ${ }^{10}$

Typically, it is very hard to assess the quality of promotion decisions empirically. One reason is that the counterfactual, i.e. the performance of the non-promoted employees on the considered position is never observable. Furthermore, personnel records such as personal assessments or employee's past performances (data that are usually hard to obtain) may not reveal which candidate best meets the requirements for the specific position to be filled.

\footnotetext{
${ }^{10}$ Note that manager PRP and manager gain sharing are two different ways of tying managers' pay to company performance. The two variables show only a weak and insignificant correlation of $r=0.07$.
} 
However, employees in a company are in a good position to judge whether indeed the best people are promoted. Of course each individual's opinion is influenced by specific personal experiences. But aggregating responses to a standardized survey item across a large number of employees within a given company should result in a reliable measure of promotion quality that can be compared between companies.

Complementing the firm level information provided by the management, we therefore exploit the employee surveys conducted in each firm to measure the quality of promotion decisions. ${ }^{11}$ The survey item "Promotions go to those who best deserve them" measures the perceived promotion quality within a firm. The item is to be answered on a 5-point Likert scale ranging from 1 "almost always untrue" to 5 "almost always true" and refers to the company as a whole. On average $28.3 \%$ of all fulltime employees in our data set affirm this statement by choosing 4 or 5 on the 5 point scale (ticking the 'top boxes').

According to our theoretical model presented in the previous section managerial incentives should lead to a higher likelihood of promoting the better employees as managers face a cost for promoting the personally favored over the more able workers. To test this prediction preserving independence of observations we use the share of affirmative answers to the Promotion item among all respondents within a firm as a measure for the quality of internal staffing decisions. The existence and strength of managers' pay for performance and the existence of gain sharing plans are our main explanatory variables. Table A1 in the appendix displays descriptive statistics of all independent variables.

\footnotetext{
${ }^{11}$ In firms with less than 500 employees all employees were asked to participate. In larger firms a representative 500-employee sample was drawn.
} 


\section{Results}

In this section we present our main results. At first we look at the aggregate data examining differences between firms with and without managerial incentives. Afterwards we explore the effects of the strength of managerial incentives and their relation to the quality of promotion decisions.

\subsection{Aggregate Data}

First, we contrast the emperical distributions of our main survey item in firms with and without managerial incentives. Figure 3 depicts the two distributions and reveals a clear difference as the percentage of workers agreeing to the item "Promotions go to those who best deserve them" is much larger in firms with manager PRP than in firms without such incentives. ${ }^{12}$ According to a two-sample Kolmogorov-Smirnov the data do not stem from the same distribution $(p=0.003)$. The difference in the average percentage of affirmative answers is as large as 6.3 percentage points and also significant applying a simple t-test $(p=0.0015)$. This notable difference is in line with our theoretical prediction suggesting that the quality of promotion decisions is indeed higher when firms provide PRP for their managers.

Repeating the analysis for firms with and without manager gain sharing plans reveals very similar results. Figure A1 displays a highly significant 9.5 percentage point difference in affirmative answers (t-test, $p=0.0014$; KS-Test, $p=0.005)$.

\footnotetext{
${ }^{12}$ Note that analyzing means rather than shares of affirmative answers leads to very similar results. Here and in the further analysis we use the share of affirmative answers (top boxes) rather than means in order to facilitate the economic interpretation of the coefficients.
} 


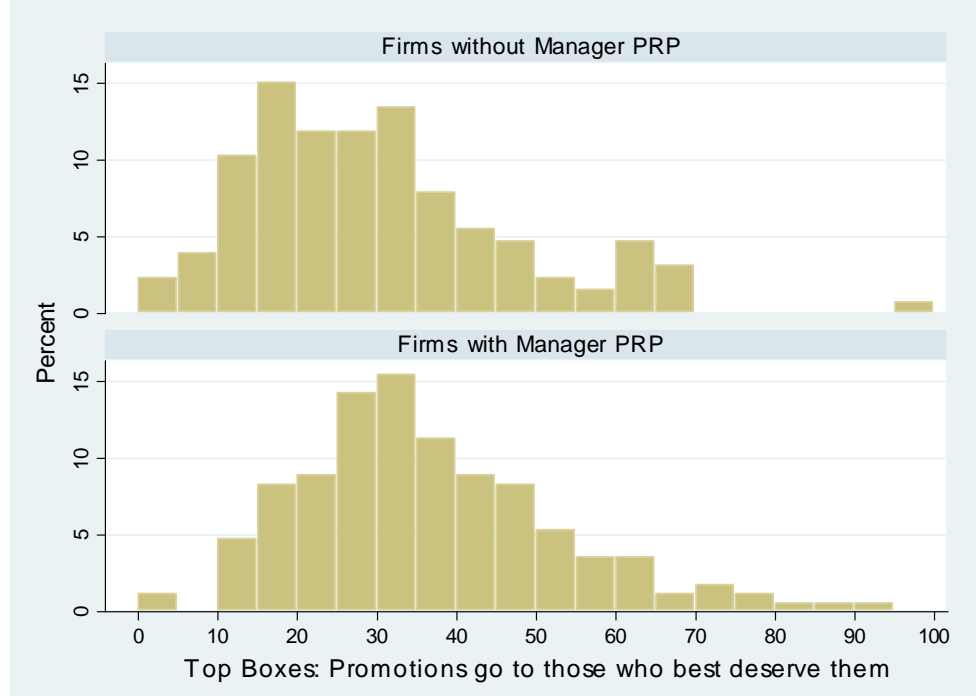

Figure 3: Favoritism in Firms with and without Manager PRP

\subsection{Regression Analysis}

We now estimate the relation between managerial incentives and our measure of favoritism controlling for key firm characteristics. The results of OLS regressions are presented in table 1. In our basic specification in column 1 of table 1 , we regress our survey item on a dummy indicating whether a firm provides performance related pay to its managers and a set of standard firm controls including two firm size dummies, 11 industry dummies and a variable indicating the presence of a works council. The coefficient of our main independent variable confirms the key hypothesis revealing a significant 7 percentage point difference in the fraction of affirmative answers between firms with and without manager PRP. This effect is substantial. By comparing predicted values at the mean of the distribution of all other independent variables the coefficient translates into a $24 \%$ increase from $29.54 \%$ affirmative answers to $36.65 \%$.

As shown in column (2) the effect of our second key independent variable 
Manager Gain Sharing is also highly significant and similar in size. Moreover, when including both in specification (3), coefficients remain stable indicating that both separately affect the quality of promotion decisions, i.e. firms which use both instruments have a substantially higher perceived quality of promotions as compared to firms which use only one of them. ${ }^{13}$

\footnotetext{
${ }^{13}$ There is no significant interaction between Manager PRP and Manager Gain Sharing.
} 


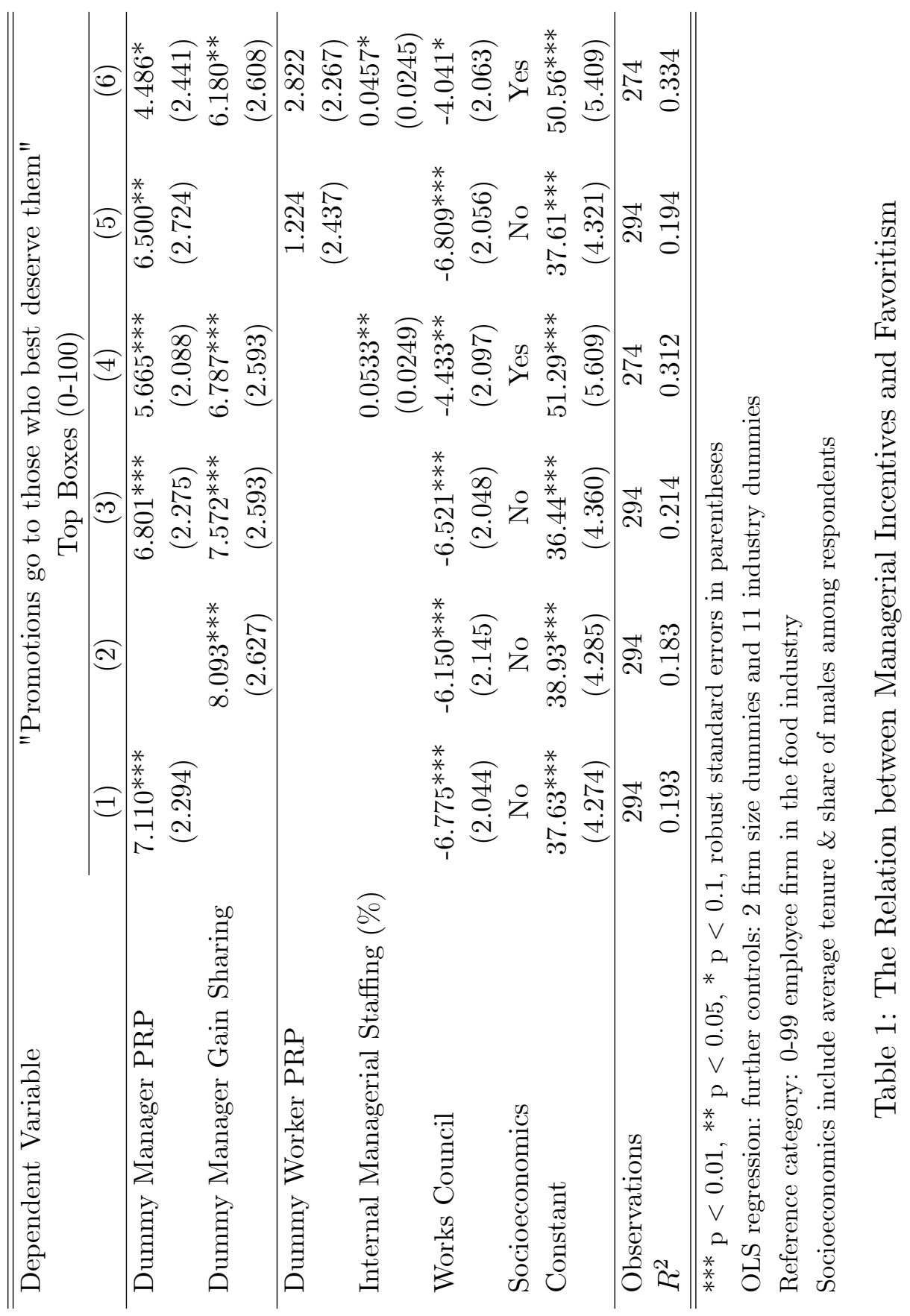


But it is of course important to control for further potentially confounding factors. In specification (4) we control for average tenure and gender composition of their surveyed workforce and the percentage of managerial positions filled internally (Internal Managerial Staffing) since higher internal staffing quotas may cause an upward bias in the respective answers. While we see that manager gain sharing as well as higher internal staffing quotas are also significantly positively related to higher promotion quality, the coefficient of our main variable of interest, the existence of manager PRP, decreases by only 1 percentage point and remains highly significant.

Finally, we use firm level information on the existence of performance related pay for workers (variable Worker PRP). Since firms who use managerial incentives are also much more likely to have performance related pay components for the rest of the workforce, the observed difference could also be due to the existence of worker PRP. One may argue that in firms with worker PRP work performance is easier to measure leaving less room for favoritism in promotion decisions. Moreover, the use of Manager PRP could just indicate that a firm is willing to use "professional" HR practices. In this case the above stated difference in promotion decisions might be partially confounded. As shown in columns $5 \& 6$ of table 1 the results for manager PRP becomes somewhat weaker ${ }^{14}$ but the effect of gain sharing remains very similar. As a further robustness check, the models reported in table A2 in the appendix only consider the subset of firms who do not pay PRP to their workers. The coefficients of Manager PRP and Manager Gain Sharing again remain similar in terms of economic and statistical significance. The results, therefore, are in line with our main theoretical hypothesis that managerial incentives either in the form of performance related pay or gain sharing plans are connected to better promotion decisions in firms.

In an alternative specification we only consider responses of employees

\footnotetext{
${ }^{14}$ Note that the variables Manager PRP and Worker PRP are highly correlated with a Pearson correlation coefficient of 0.58 .
} 
with at least 2 years of firm tenure as company newcomers may be inexperienced and therefore incapable of judging promotion quality at their current workplace. The presented results in table A3 show that the noise is indeed reduced and in particular the coefficients of Manager PRP gain in statistical significance.

In the next step we take the strength of managerial incentives into account. Our theoretical model suggests that higher managerial incentives should lead to less favoritism suggesting a monotone effect of managerial incentives on favoritism. However, as indicated by figure 1, the effect should be non-linear. For instance, when preferences for favoritism are not too strong, already weak managerial incentives may have a substantial effect on the quality of promotion decisions. Any further increase in managerial incentives may provide only little further improvement.

In table 2 we therefore regress our main dependent variable on the strength of manager PRP (column $1 \& 2$ ). In column 3 we test for a quadratic functional form of managerial incentives, while column 4 allows a non-parametric functional form by including 3 interval dummies for the strength of manager PRP with the reference category being firms without manager PRP.

The coefficients in columns $1 \& 2$ in table 2 indicate a positive slope. However, the last two columns reveal that even firms in which less than $10 \%$ of the managers' total wages depend on performance exhibit significantly better promotion decisions. Increasing managerial incentives beyond 10\% does not additionally increase the share of affirmative answers. ${ }^{15}$ This result confirms our theoretical prediction and suggests that already rather weak managerial incentives indeed help to overcome favoritism in promotion decisions.

\footnotetext{
${ }^{15}$ Note that the coefficients of the interval dummies are not significantly different from one another.
} 


\begin{tabular}{|c|c|c|c|c|}
\hline \multirow[t]{3}{*}{ Dependent Variable } & \multicolumn{4}{|c|}{$\begin{array}{c}\text { "Promotions go to those who best deserve them" } \\
\text { Top Boxes }(0-100)\end{array}$} \\
\hline & \multicolumn{4}{|c|}{ All Firms } \\
\hline & $(1)$ & $(2)$ & $(3)$ & $(4)$ \\
\hline Manager PRP & $\begin{array}{l}0.142^{* *} \\
(0.0690)\end{array}$ & $\begin{array}{l}0.132^{* *} \\
(0.0645)\end{array}$ & $\begin{array}{r}0.305^{* *} \\
(0.122)\end{array}$ & \\
\hline Manager $\mathrm{PRP}^{2}$ & & & $\begin{array}{c}-0.00298^{* *} \\
(0.00147)\end{array}$ & \\
\hline Manager PRP 1-10\% & & & & $\begin{array}{l}6.424^{* *} \\
(2.737)\end{array}$ \\
\hline Manager PRP 11-20\% & & & & $\begin{array}{l}4.425^{*} \\
(2.338)\end{array}$ \\
\hline Manager PRP > 20\% & & & & $\begin{array}{c}6.013^{* *} \\
(2.756)\end{array}$ \\
\hline Dummy Manager Gain Sharing & & $\begin{array}{c}6.792^{* * *} \\
(2.612)\end{array}$ & $\begin{array}{c}6.580 * * \\
(2.601)\end{array}$ & $\begin{array}{c}6.774^{* * *} \\
(2.587)\end{array}$ \\
\hline Internal Managerial Staffing (\%) & $\begin{array}{c}0.0651^{* * *} \\
(0.0248)\end{array}$ & $\begin{array}{r}0.0558^{* *} \\
(0.0251)\end{array}$ & $\begin{array}{l}0.0580^{* *} \\
(0.0253)\end{array}$ & $\begin{array}{r}0.0550^{* *} \\
(0.0250)\end{array}$ \\
\hline Works Council & $\begin{array}{c}-5.190^{* *} \\
(2.122)\end{array}$ & $\begin{array}{c}-4.639^{* *} \\
(2.142)\end{array}$ & $\begin{array}{c}-4.589^{* *} \\
(2.143)\end{array}$ & $\begin{array}{c}-4.706^{* *} \\
(2.119)\end{array}$ \\
\hline Socioeconomics & Yes & Yes & Yes & Yes \\
\hline Constant & $\begin{array}{c}54.25^{* * *} \\
(5.517)\end{array}$ & $\begin{array}{c}53.92^{* * *} \\
(5.481)\end{array}$ & $\begin{array}{c}53.01^{* * * *} \\
(5.566)\end{array}$ & $\begin{array}{c}52.41^{* * *} \\
(5.581)\end{array}$ \\
\hline Observations & 271 & 271 & 271 & 271 \\
\hline$R^{2}$ & 0.287 & 0.302 & 0.308 & 0.314 \\
\hline
\end{tabular}

*** $\mathrm{p}<0.01,{ }^{* *} \mathrm{p}<0.05,{ }^{*} \mathrm{p}<0.1$, robust standard errors in parentheses

OLS regression: further controls: 2 firm size dummies and 11 industry dummies

Reference category: 0-99 employee firm in the food industry

Reference category in model (4): Firms without manager PRP

Socioeconomics include average tenure \& share of males among respondents

Table 2: The Relation between the Strength of Managerial Incentives and Favoritism 


\section{Conclusion}

When performance is not perfectly observable promotion decisions are frequently based on subjective performance measures. If managers have personal preferences for certain workers they have an incentive to distort performance ratings by promoting favored workers rather than most able workers. We theoretically show that favoritism can reduce company profits not only by putting the wrong people into management positions but also by reducing incentives for workers to exert effort during the tournament. Managerial incentives can constrain favoritism in promotion decisions by realigning managers' and firm interest whereas even rather weak managerial incentives may generate strong efficiency gains.

We empirically tested the theoretical prediction using a unique representative matched employer-employee data set. The empirical analysis confirms our theoretical result as promotion quality is significantly higher in firms in which managers receive performance related pay or participate in gain sharing plans. Indeed this higher perceived quality of promotion decisions should translate in higher company performance as, not only the probability that the best and not the best-liked employees are promoted increases, but also because stronger merit-based promotions should lead to a more motivated workforce.

\section{References}

Anderson, R. C. and D. M. Reeb (2003). Founding-family ownership and firm

performance: Evidence from the s\&p 500. The Journal of Finance 58(3), $1301-1327$.

Bandiera, O., I. Barankay, and I. Rasul (2009). Social connections and incentives in the workplace: Evidence from personnel data. Econometrica 7 r, 1047-1094. 
Bennedsen, M., K. M. Nielsen, F. Perez-Gonzalez, and D. Wolfenzon (2007). Inside the familiy firm: The role of families in succession decisions and performance. the Quarterly Journal of Economics, 647-690.

Bjerke, R., J. Cleveland, R. Morrison, and W. Wilson (1987). Officer fitness report evaluation study. Report TR-88-4 (Navy Personnel Research and Development Center. Washingtion DC).

Bloom, N. and J. Van Reenen (2007). Measuring and explaining management practices across firms and countries. Quarterly Journal of Economics, MIT Press 122, 1351-1408.

Bloom, N. and J. Van Reenen (2010). New approaches to surveying organizations. American Economic Review, American Economic Association 100, 105-109.

Breuer, K., P. Nieken, and D. Sliwka (2010). Social ties and subjective performance evaluations: An empirical investigation. IZA DP No. 4913.

DeGroot, M. (1970). Optimal Statistical Decisions. New York: McGraw-Hill.

Ittner, C. D., D. F. Larcker, and M. W. Meyer (2003). Subjectivity and the weighting of performance measures: Evidence from a balanced scorecard. The Accounting Review 78, 725-758.

Kramarz, F. and O. N. Skans (2007). With a little help from my parents: Family networks and youth labor market entry. Crest Working Paper.

Lazear, E. P. and S. Rosen (1981). Rank-order tournaments as optimum labor contracts. Journal of Political Economy 89, 841-864.

Longenecker, C. O., H. P. Sims, and D. A. Gioia (1987). Behind the mask: The politics of employee appraisal. The Academy Of Management Executive 1, 183-193. 
Marsh, R. M. (1960). Bureaucratic constraints on nepotism in the ch'ing period. The Journal of Asian Studies 19, 117-133.

Prendergast, C. and R. Topel (1996). Favoritism in organizations. Journal of Political Economy 104, 958-978.

Prendergast, C. J. (2002). Uncertainty and incentives. Journal of Labor Economics 20, 115-37.

Prendergast, C. J. and R. H. Topel (1993). Discretion and bias in performance evaluation. European Economic Review 37, 355-65.

Pérez-González (2006). Inherited control and firm performance. American Economic Review 96, 1559-1588.

Sraer, D. and D. Thesmar (2007). Performance and behavior of family firms: Evidence from the french stock market. Journal of the European Economic Association 5(4), 709-751.

Vilallonga, B. and R. Amit (2006). How do family ownership, control and management affect firm value? Journal of Financial Economics 80, 385417. 


\section{Appendix}

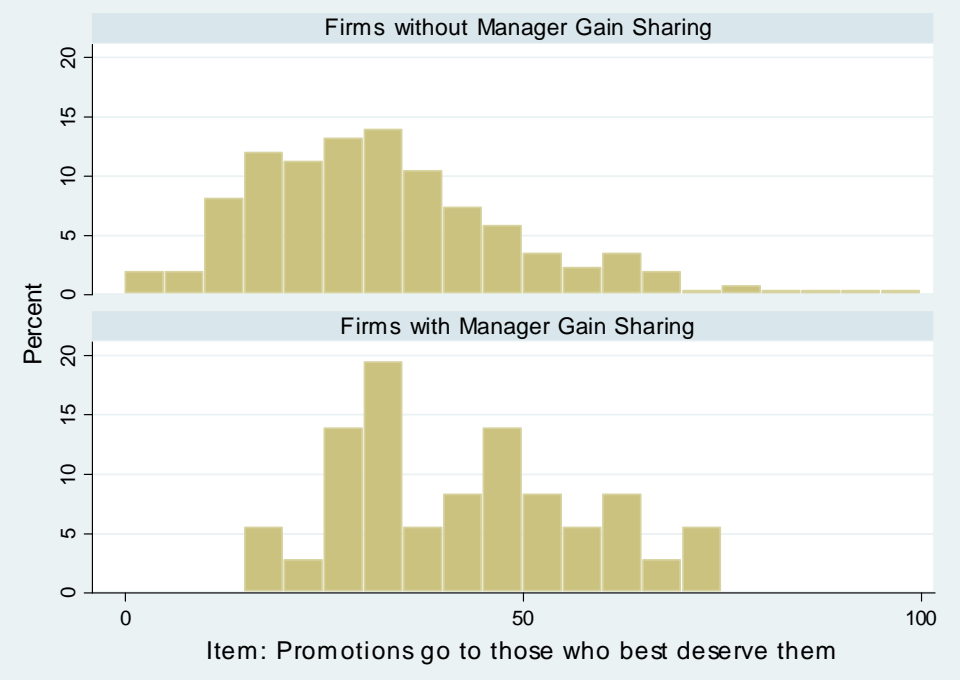

Figure A1: Favoritism in Firms with and without Manager Gain Sharing 


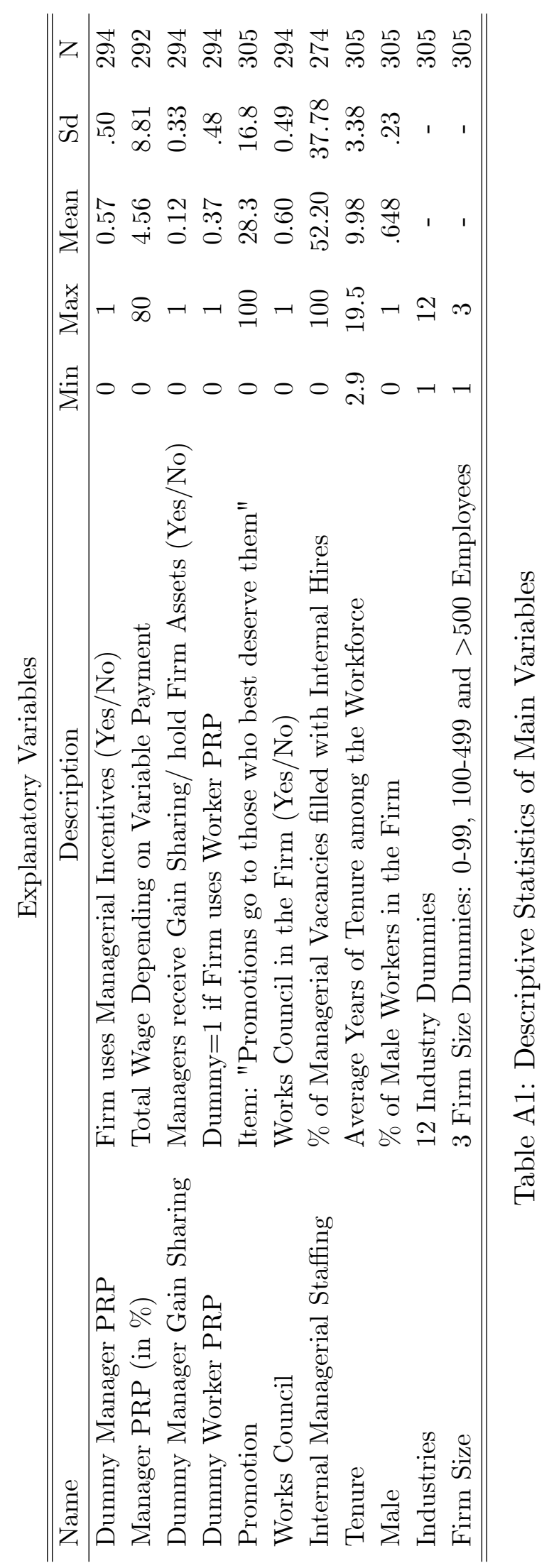




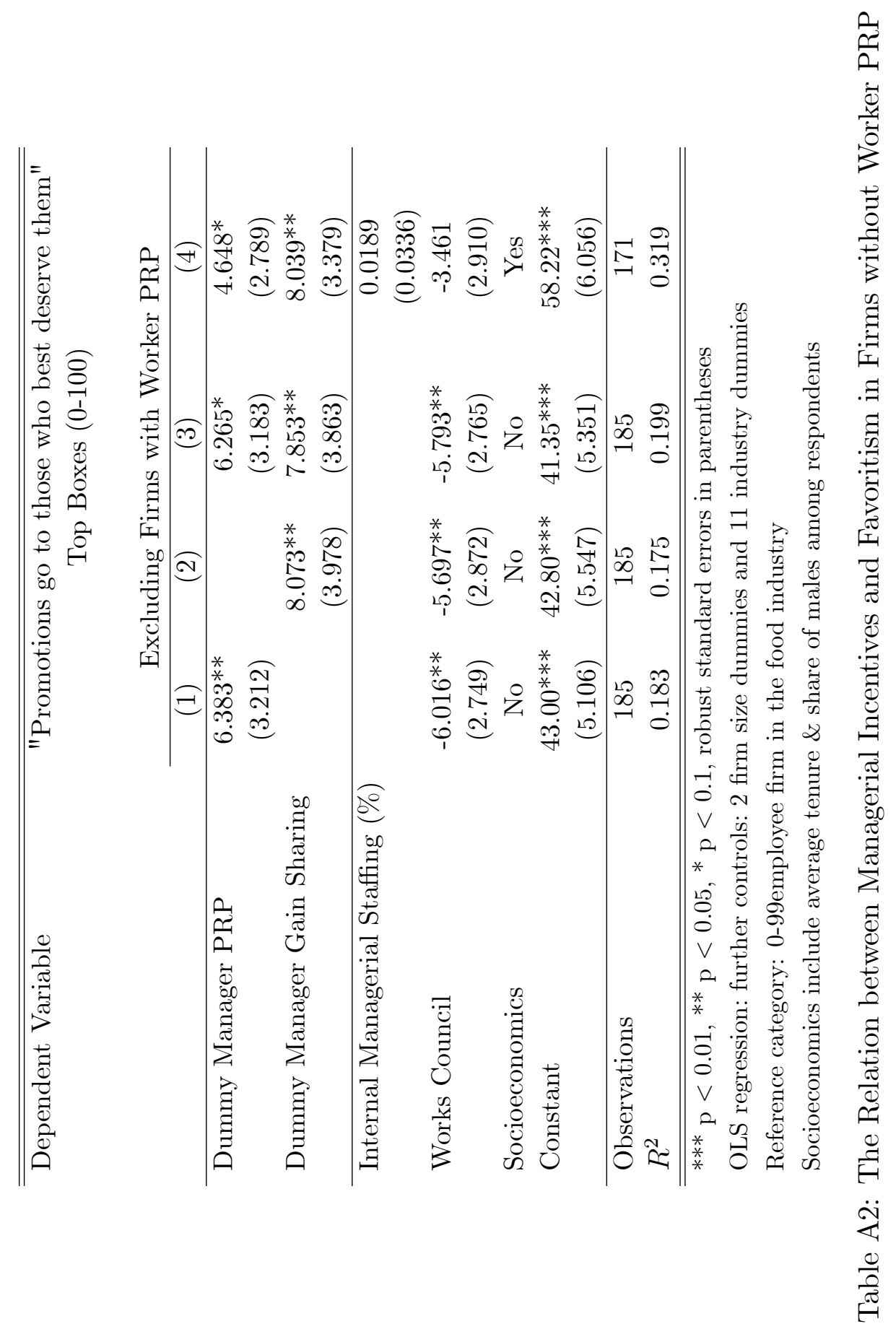




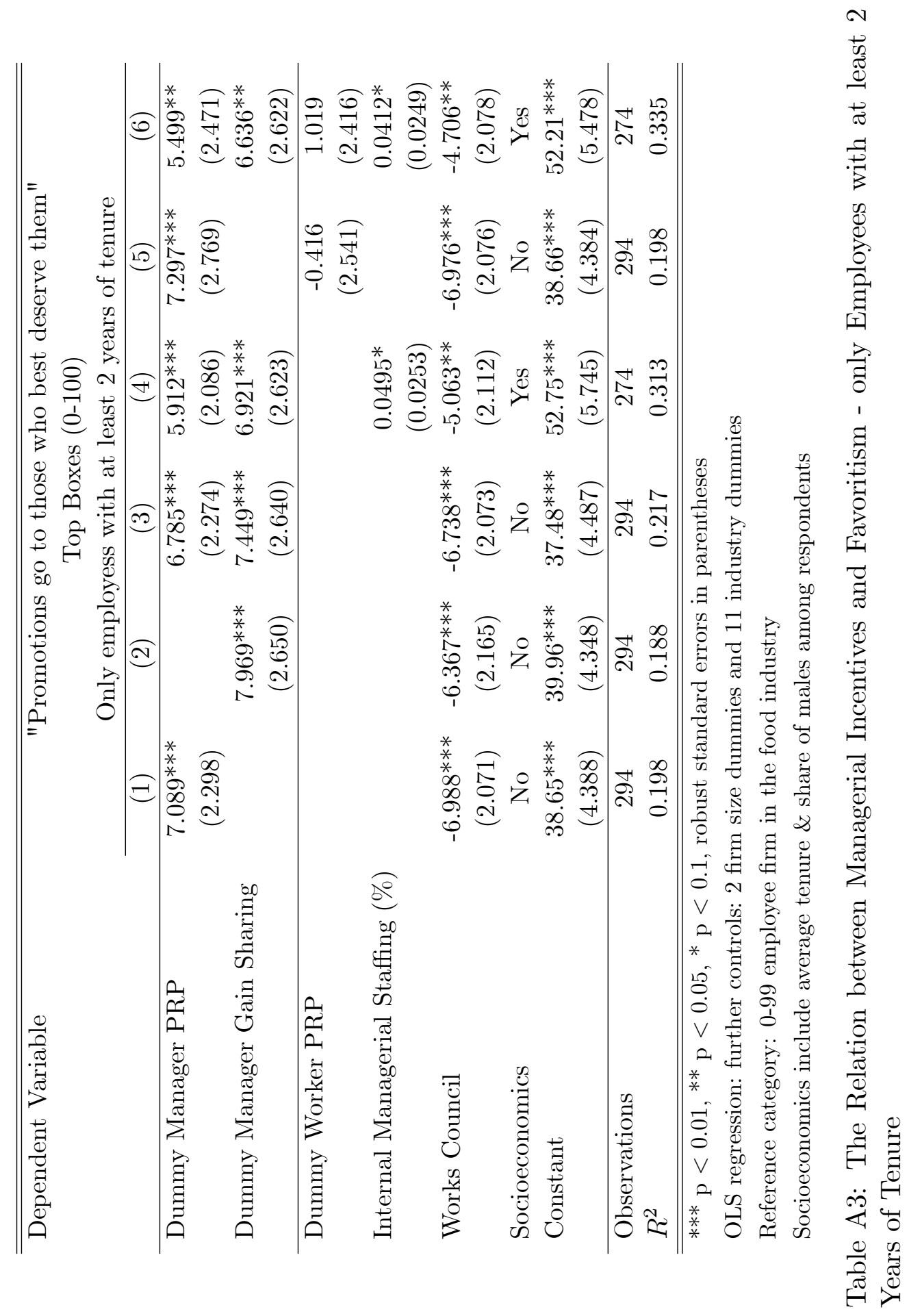

